\title{
One-pot Syntheses of Metallic Hollow Nanoparticles of Tin and Lead
}

\author{
Gaehang Lee, ${ }^{\dagger \ddagger}$ Sang-Il Choi, ${ }^{\dagger}$ Young Hwan Lee, ${ }^{\dagger}$ and Joon T. Park ${ }^{\dagger,}$ \\ Department of Chemistry and School of Molecular Science (BK 21), Korea Advanced Institute of Science and \\ Technology (KAIST), Daejeon 305-701, Korea. "E-mail: joontparkakaist.ackr. \\ +Diwision of Materials Science, Korea Basic Science Institute (KBSI), Daejeon 305-333. Korea \\ Received December 2, 2008. Accepted March 27, 2009
}

\begin{abstract}
Hollow $\mathrm{Sn}$ and $\mathrm{Pb}$ nanoparticles have been prepared by a rapid injection of an aqueous solution of $\mathrm{SnCl}_{2}$ poly (vinylpyrrolidone) ( $\mathrm{PVP}$, surfactant) and $\mathrm{Pb}(\mathrm{OAc})_{2} \cdot 3 \mathrm{H}_{2} \mathrm{O}-\mathrm{PVP}$ into an aqueous solution of sodium borohydride (reducing agent) in simple, one-pot reaction at room temperature under an argon atmosphere, respectively. The two hollow nanoparticles have been fully characterized by TEM, HRTEM, SAED, XRD, and EDX analyses. Upon exposure to air, the black $\mathrm{Pb}$ hollow nanoparticles are gradually transformed into a mixture of $\mathrm{Pb}$, litharge (tetragonal $\mathrm{PbO}$ ), massicot (orthorhombic $\mathrm{PbO}$ ), and $\mathrm{Pb} \mathrm{O}_{8}$. The order and speed of mixing of the reactants between the metal precursor-PVP and the reductant solutions and stoichiometry of all the reactants are crucial factors for the formation of the two hollow nanocrystals. The $\mathrm{Sn}$ and $\mathrm{Pb}$ hollow nanoparticles were produced only when $1:(1.5-2)$ and 1.3 ratios of the $\mathrm{Sn}$ and $\mathrm{Pb}$ precursors to $\mathrm{NaBH}_{+}$were employed with a rapid injection, respectively.
\end{abstract}

Key Wonds: Hollow, PVP, $\mathrm{NaBH}_{4}$. Tin, Lead

\section{Introduction}

Nanostnictures with an empty core are fascinating materials due to several advantages such as low density. high surface area. lighter weight. and reduced cost compared to their solid counterparts. In particular, hollow nanomaterials exhibit superior characteristics in their applications such as cataly sis. ${ }^{1}$ fuel cell. ${ }^{2-3}$ biotechnology, ${ }^{+6}$ lubricant, ${ }^{3}$ and nanoreactor. ${ }^{8}$ Metallic hollow nanoparticles have been prepared from the general sy'nthetic strategy that the surface of templates (e.g. silver. ${ }^{9.12}$ selenium, ${ }^{13}$ cobalt, ${ }^{214}$ polymer late..$^{15,16}$ and silica ${ }^{1,17.19}$ ) is covered by desired metals. and then the core templates were selectively removed through calcination wet chemical etching, and galvanic replacement. Great challenges still remain. however. in preparing hollow spheres via one-step thermal solution reactions.

Tin nanostructures have been shown to exhibit a high catalytic activity in the dehydrogenation of isobutene, ${ }^{\text {?a }}$ and enhanced capacity and cycling stability when alloyed with lithium for secondary battery applications. ${ }^{21}$ Tin nanoparticles have been prepared through the methods of thermal evaporation of a bulk tin ball. $2=$ reaction of $\mathrm{SnCl}_{4}, \mathrm{Mg}_{2} \mathrm{Sn}$. and $n-\mathrm{C}_{4} \mathrm{H}_{4} \mathrm{Li}$ in ethylene glycol dimethyl ether, ${ }^{23}$ and reduction of $\mathrm{SnCl}_{4} \cdot 5 \mathrm{H}_{3} \mathrm{O}$ by tetraoctylammonium bromide in dichloromethane. ${ }^{31}$ Lead nanostructures are attractive materials for its potential applications in superconductor ${ }^{2+}$ and photonic crystal ${ }^{25}$ Lead nanoparticles have been prepared by reduction of $\mathrm{Pb}\left[\mathrm{N}\left(\mathrm{SiMe}_{3}\right)_{2}\right)=$ by $\mathrm{H}_{2} \mathrm{Al}\left(\mathrm{O}^{\prime} \mathrm{Bu}\right)^{? 6}$ and polvol reduction of $\mathrm{Pb}\left(\mathrm{CH}_{3} \mathrm{COO}\right)_{2} \cdot 3 \mathrm{H}_{2} \mathrm{O}^{\text {.5 }}$

Herein we report simple. one-pot syntheses of hollow Sn and $\mathrm{Pb}$ nanoparticles by employing $\mathrm{SnCl}_{2}$ or $\mathrm{Pb}(\mathrm{OAc})_{2}: 3 \mathrm{H}_{2} \mathrm{O}$ $\left(\mathrm{Ac}=\mathrm{CH}_{3} \mathrm{CO}\right)$ as a precursor, sodium borohydride as a reducing agent. and poly(vinylpyrrolidone) (PVP) as a surfactant under extremely mild conditions at room temperature.

\section{Experimental Section}

All reactions were carried out under an argon atmosphere with use of standard Schlenk techuiques. Ultra-pure water was obtained from Milli-Q immediately before use. $\mathrm{SnCl}_{2}$ ( $98 \%$. Strem Chenicals). $\mathrm{Pb}(\mathrm{OAc}) \cdot 3 \mathrm{H}_{2} \mathrm{O}(99 \%$. Yakuri Pure Chemicals), poly(vinylpyrrolidone) (PVP, $\mathrm{M}_{w} \approx 55.000$ Dalton Sigma-Aldrich), sodium borohydride ( $98 \%$, Aldrich). and 1-methyl-2-pyrrolidone ( $99 \%$, Aldrich) were used without further purification.

The hollow Sn nanoparticles $(10 \pm 1.4 \mathrm{~lm}$ in diameter with a $5 \pm 0.9 \mathrm{~nm}$ hole) were prepared by a rapid injection of a mixture of $\mathrm{SnCl}_{\Sigma}(50 \mathrm{mg}$ ) and poly (vinyl py rrolidone) (PVP) (295 mg. $\left.\mathrm{M}_{w}=55,000\right)$ in ultra-pure $\mathrm{H}_{2} \mathrm{O}(2 \mathrm{~mL}$ ) into an aqueous $\mathrm{NaBH}_{4}(10 \mathrm{mg})$ solution $\left(\mathrm{H}_{2} \mathrm{O} .8 \mathrm{~mL}\right)$ under an argon atmosphere at room tentperature. The reaction was allowed to proceed for $10 \mathrm{~min}$. To the resulting reaction mixture was added ethanol $(20 \mathrm{~mL})$ and centrifuged at $14,000 \mathrm{rpm}$ for 30 min to remove byproducts and excess PVP. Similar repeated purification (3 times) with ethanol $(20 \mathrm{~mL}$ ) gave a black precipitate, which could be readily re-dispersed in various hydrophilic solvents such as methanol. ethanol. and water. The hollow $\mathrm{Pb}$ nanocry stals $(51 \pm 7 \mathrm{~nm}$ in diameter with a 30 $\pm 4 \mathrm{~nm}$ hole) were similarly prepared by the procedure described above for the preparation of the hollow Sn nanoparticles except that $\mathrm{Pb}(\mathrm{OAc})=3 \mathrm{H}_{2} \mathrm{O}$ (70 mg). $\mathrm{PVP}(205 \mathrm{mg})$. and $\mathrm{NaBH}_{4}(10.5 \mathrm{mg})$ were used.

The $\mathrm{Sn} . \mathrm{Pb}$. and conposite $(\mathrm{Pb}$, litharge $(\mathrm{PbO})$. massicot $(\mathrm{PbO})$, and $\mathrm{Pb}_{5} \mathrm{O}_{3}$ ) hollow nanocry stals were characterized by XRD (Rigaku D/MAX-RB (12 kW) diffractometer using graphite-monochromatized $\mathrm{Cu}-\mathrm{K} \alpha$ radiation at $40 \mathrm{kV}$ and 45 $\mathrm{mA}$ and Bruker D8 Advance ( $3 \mathrm{~kW}$ ) with Vantec detector diffractometer using $\mathrm{Ge}(111)-\mathrm{Cu} \mathrm{Kal}$ radiation at $50 \mathrm{kV}$ and $40 \mathrm{~mA}$ ). TEM (low resolution: Omega EM912 operated at $120 \mathrm{kV}$; high resolution: Plilips F20Tecnai operated at 200 
$\mathrm{kV}$ : EDX line analysis: Tecnai G2 F30 S-TWIN operated at $300 \mathrm{kV}$ ), and selected arca clectron diffraction (SAED) pattems attached to EM912. Samples for TE.M investigations were prepared by placing an aliquol of ethanol solution onto an amorphous carbon substrate supported on a copper grid and allowing the grid to dry at room temperature.

\section{Results and Discussion}

Hollow Sn and Pb nanoparticles have becn prepared by a rapid injection of an aqucous solution of $\mathrm{SnCl}$-poly (vinvlpvrrolidonc) (PVP. surfactant) and $\mathrm{Pb}(\mathrm{OAc})_{2} \cdot 3 \mathrm{H}_{2} \mathrm{O}$-PVP into an aqucous solution of sodium borohydride (reducing agent) in one-pot reaction at room temperature under an argon atmosphere, respectively. The evidence for the hollow nature of nanocrystalline $\mathrm{Sn}$ and $\mathrm{Pb}$ is seen in the TEM and EDX analyses of the materials. Both TEM (Figure l) and HRTEM (the insets) images of $\mathrm{Sn}$ or $\mathrm{Pb}$ nanoparticles reveal that the middle par is brighter than the edge of the particles, clearly indicating a well-defined void. The hollow Sn manoparticles tend to be collapsed by the c-bean during the TEM mcasurement (Figure Sl in the supporting information). Furthermore. Figure 2 shows the EDX line analy sis across a single $\mathrm{Pb}$ particle (Tecnai G2 F30 S-TWIN operated at $300 \mathrm{kV} .60$ pixcl size. and $3 \mathrm{sec}$ dwcll time). The $\mathrm{Pb} \mathrm{L}$ line decreases from the outer wall toward the center. We were not able to obtain a woll-defined $S n$ line analysis, because the Sn nanostructure

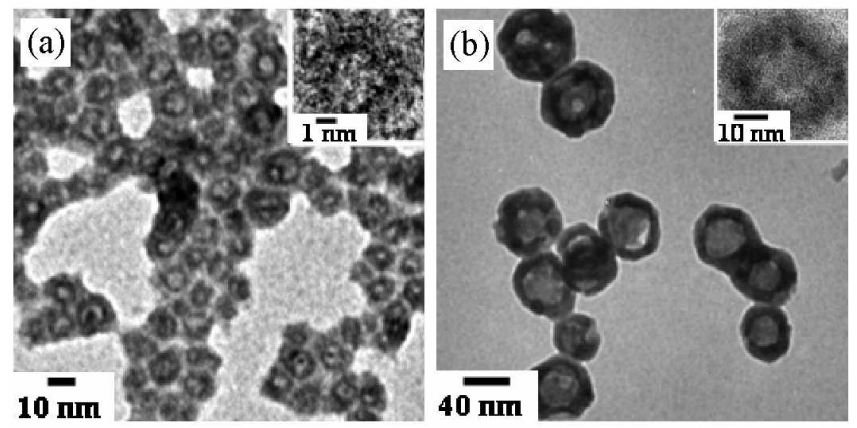

Figune 1. THM images of hollow (a) Sn and (b) Pb nanoparticles. (insed: I IRl lim images of a single hollow (a) Sn and (b) l'b nanoparticle.)

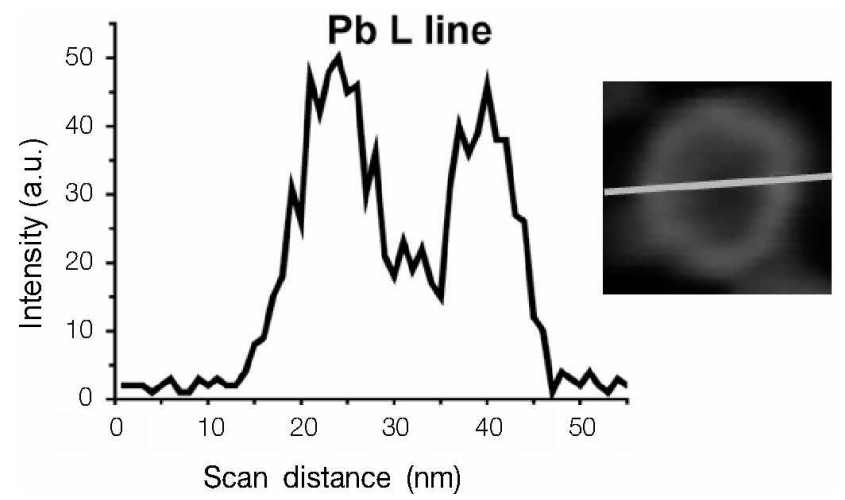

Figure 2. The li]DX line analvsis across a single hollon Plo nanopartiele (dark-lield THM intige ol ca. 38 nm nanoparticle). collapsed when exposed to the e-beam of the TEM as indicated above. The XRD data (Figure 3) of the hollow Sn and $\mathrm{Pb}$ nanoparticles are consistent with a tetragonal structure for Sn (JCPDS card No. 65-2631) and a cubic structure for Pb (JCPDS card No. 65-2873). The SAED pattern of the hollow: Sil nanoparticles in Figure 4(a) matchs well with the XRD data of this matcrial.

The following results render some insight into this notel phenomena of the formation of the hollow nanoparticles. The hollow nanoparticles form only in rers limitcd ranges of stoichiontetric ratios of the precursor. surfactant. and reducing agent. as indicated in the synthetic procedures. The hollow natroparticles are fornted in the early stage of the reactions within a few minutes. The $\mathrm{Pb}$ hollow nanoparticles were produced only when a $1: 3$ ratio of the $\mathrm{Pb}$ precursor to $\mathrm{NaBH}_{4}$ was emplosed with a rapid injection. Upon exposure to air. the color of the solution containing black $\mathrm{Pb}$ hollow nanoparticles gradually changed from black to pale yellow. The SAED (Figure 4(b)), XRD (Figure S3). and HRTEM (Figure S4) data of these pale yellow particles indicated that a mixture of $\mathrm{Pb}$. litharge (1etragonal $\mathrm{PbO}$ ), massicon (orthorhombic $\mathrm{PbO}$ ), and $\mathrm{Pb}_{3} \mathrm{O}_{3}$ formed. When a $\mathrm{Pb}(\mathrm{OAc})_{2} \cdot 3 \mathrm{H}_{2} \mathrm{O}$ aqueous solution instead of a $\mathrm{Pb}(\mathrm{OAc}) \times 3 \mathrm{H} \cdot \mathrm{O}$-PVP solution was added to an aqueous solution of $\mathrm{NaBH}_{+}$and PVP, only solid nanoparticles $(5 \perp 1.8 \mathrm{~nm})$ were formed. and their hollow counterparts were not obseried.

In the case of Sn nanocry stal formation, a dropwise addition of an aqueous mixture of $\mathrm{SnCl}_{2}$ and PVP to an aqueous solution of $\mathrm{NaBH}_{4}$ resulted in the formation of mixed nanoparticles with solid $11 \pm 1.7 \mathrm{~mm}(89 \%)$ and hollow $9 \pm 1.6 \mathrm{~nm}$ with a 5 $\pm 0.8 \mathrm{~nm}$ hole ( $11 \%$ ) (Figure $\mathrm{S} 5(\mathrm{a})$ ). If reagents are added in a dropwise and reverse way, this also led to mixed nanoparticles
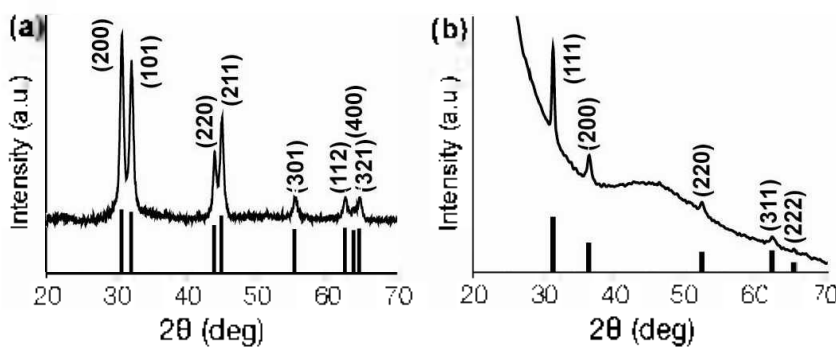

Figure 3. XRI) puttens of hollow (a) Sn and (b) Pb manoparticles in a PMMA sample holder (Figure $\$ 2$ ). The standard peaks from the KCPIS cards are shown as bar diagrams at the bottom.
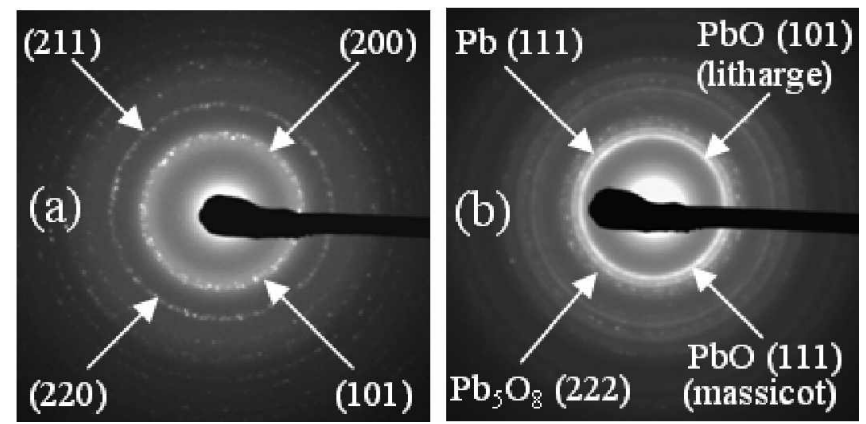

Figune 4. $S A F I)$ patterns ol hollow (a) Sin and (b) l’b nátoparticles. 


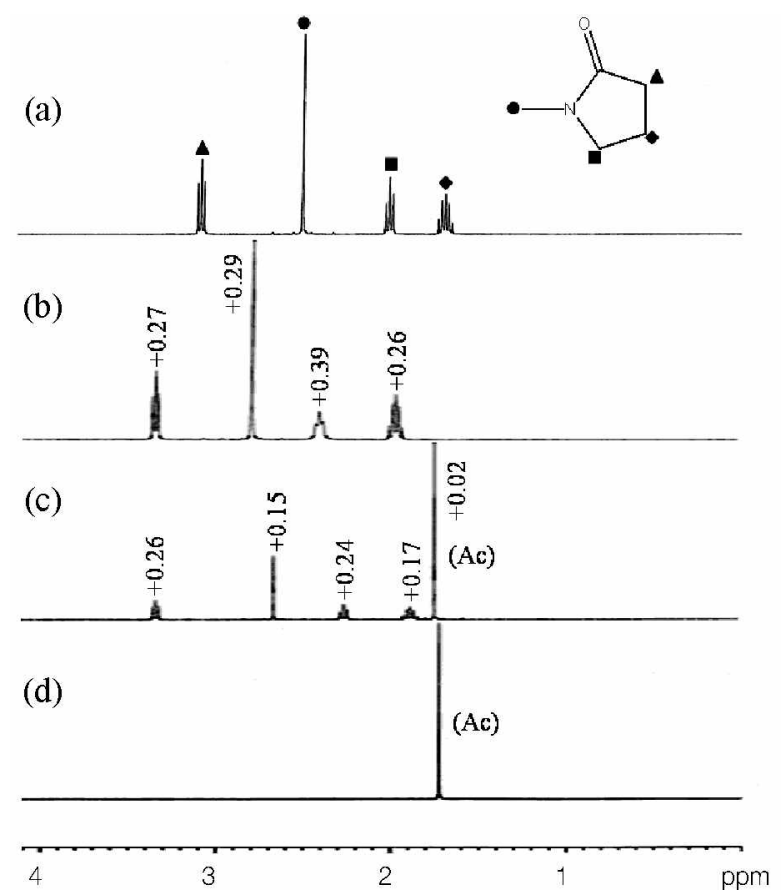

Figure 5. 'H NMR spectra of (a) 1-methyl-2-pynolidone (mpy), (b) $\mathrm{S}_{11 C l}-1 \mathrm{mpy}$, (c) $\mathrm{Pb}(\mathrm{OAc})_{2} \cdot 3 \mathrm{H}_{2} \mathrm{O}-112 \mathrm{py}$, and (d) $\mathrm{Pb}(\mathrm{OAc})_{2} \cdot 3 \mathrm{H}_{2} \mathrm{O}$. Numbers provided in (b) and (c) are relative chemical shift differences from values for pure mpy and $\mathrm{Pb}(\mathrm{OAc})_{2}=3 \mathrm{H}_{2} \mathrm{O}$, respectively.

of solid $10 \pm 1.5 \mathrm{~nm}(63 \%)$ and hollow $9 \pm 1.1 \mathrm{~nm}$ with a $5 \pm$ 0.6 run hole (37\%) (Figure S5(b)). However, in a rapid injection of $\mathrm{SnCl}_{2}-\mathrm{PVP}$ to $\mathrm{NaBH}_{4}$, the shape of hollow nanoparticles was strongly dependent on the stoichiometric $\mathrm{NaBH}_{4}$ to $\mathrm{Sn}$ precursor ratio. With (i) 1 . (ii) 1.5 . (iii) 2 , and (iv) 3 equivalent ratios of $\mathrm{NaBH}_{4}$ to $\mathrm{Sn}$. (i) solid $9 \pm 0.7 \mathrm{~nm}$, (ii) hollow $9 \pm 1.1$ num with a $2 \pm 0.9 \mathrm{~nm}$ hole, (iii) hollow $10 \pm 1.4$ num with a $5 \pm$ $0.9 \mathrm{~nm}$ hole. and (iv) solid $\mathrm{II} \pm 1.5 \mathrm{~nm}(87 \%)$ and hollow $9 \pm$ $0.7 \mathrm{~nm}$ with a $3 \pm 1.1 \mathrm{~nm}$ hole $(13 \%)$ of $\mathrm{Sn}$ particles. were produced. respectively (Figure \$6). Hollow Sn particles were only formed with a $1:(1.5-2)$ ratio of the $\mathrm{Sn}$ precursor to $\mathrm{NaBH}_{4}$. These results imply that the interaction between metal precursors and PVP as well as rapid reduction of metal precursors are the critical factors for the production of hollow structures.

The PVP surfactant is the only one that yields the hollow nanoparticles among various surfactants tested such as cetyltrimethylammonium bromide. poly(propylene carbonate), and polyacrylamide. The insoluble $\mathrm{SnCl}_{2}$ precursor in water becomes soluble upon mixing with the PVP ligand implying that $\mathrm{Sn}^{2+}\left(\mathrm{Pb}^{2-}\right.$ in the other case) strongly interacts with PVP as previously reported ${ }^{2 *}$ The ${ }^{1} \mathrm{H}$ NMR spectra of an aqueous solution of $\mathrm{SnCl}_{-}$and 1-methyl-2-pyrrolidone (mpy) and that of $\mathrm{Pb}(\mathrm{OAc})_{-} \cdot 3 \mathrm{H}_{2} \mathrm{O}$ and mpy reveal av. 0.30 and $0.21 \mathrm{ppm}$ downfield shifts compared to the pure mpy peaks. respectively. as shown in Figure 5. The mpy was employed instead of PVP in order to observe sharp NMR signals. The $\mathrm{Sn}^{2+}$-PVP and $\mathrm{Pb}^{\text {i- }}$-PVP interactions exhibit a red shift of PVP $v(\mathrm{CO})$ of $69.9 \mathrm{~cm}^{-1}$ and $4.7 \mathrm{~cm}^{-1}$ relative to PVP, respectively, in the $\mathbb{R}$ spectra (Figure S7). The $\mathrm{Pb}^{2+}$-PVP interaction shows a blue shift of the acetate $v(\mathrm{CO})$ of $\mathrm{o} .2 .9 \mathrm{~cm}^{-1}$ relative to the pure

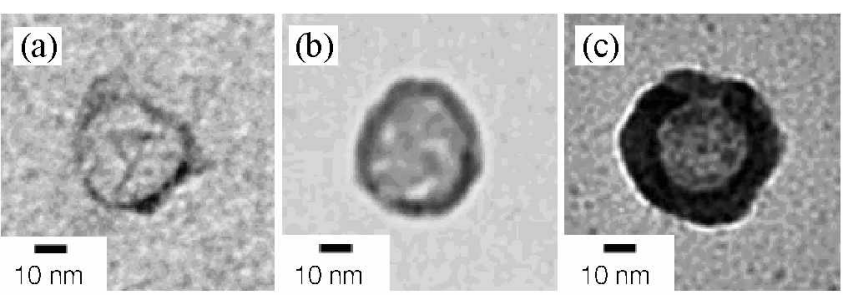

Figure 6. Size growth of hollow $\mathrm{Pb}$ nanoparticles: (a) $43 \mathrm{~nm}$ with a shell thickness of $1.7 \mathrm{~nm}$ immediately after injection. (b) $44 \mathrm{~nm}$ with a $4.5 \mathrm{~nm}$ shell thickness after $1 \mathrm{~min}$, (c) $56 \mathrm{~nm}$ with a $11 \mathrm{~nm}$ shell thickness after $10 \mathrm{~min}$

$\mathrm{Pb}(\mathrm{OAc})_{2} \cdot 3 \mathrm{H}_{2} \mathrm{O}$. These results suggest that the interaction of $\mathrm{SnCl}_{2}$ with $\mathrm{PVP}$ is stronger than that of $\mathrm{Pb}(\mathrm{OAc})_{2} \cdot 3 \mathrm{H}_{2} \mathrm{O}$ with PVP. Tin ion with smaller chloride ligands is. presumably. more open to the PVP coordination than lead ion with larger acetate ligands. The interactions of $\mathrm{Sn}$ and $\mathrm{Pb}$ nanoparticles with PVP reveal a red shift of PVP $v(C O)$ of $11.2 \mathrm{~cm}^{.1}$ and $19.8 \mathrm{~cm}^{-1}$ relative to PVP. respectively. In comparison, a red shift of the PVP carbonyl frequency of $c a .60 \mathrm{~cm}^{-1}$ has been reported due to the strong $\mathrm{C}=\mathrm{O} \rightarrow \mathrm{Pt}$ interaction for $\mathrm{Pt}$ nanoparticles capped with the PVP surfactant. ${ }^{28}$

The TEM intage of the sample taken inmediately after injection of $\mathrm{Pb}(\mathrm{OAc})_{2} \cdot 3 \mathrm{H}_{2} \mathrm{O}$-PVP solution into a $\mathrm{NaBH}_{4}$ solution showed hollow nanoparticles of $43 \mathrm{~nm}$ with a thin shell thickness of $1.7 \mathrm{~mm}$ (Figure 6(a)). and the size evolution was observed as the reaction proceeds [ $44 \mathrm{~nm}$ with a $4.5 \mathrm{~nm}$ shell thickness after 1 nin (Figure $6(\mathrm{~b})$ ) and $56 \mathrm{~nm}$ with a 11 $\mathrm{nm}$ shell thickness after $10 \mathrm{~min}$ (Figure 6(c))]. Proposing detailed pathways for the formation of hollow nanoparticles from our data provided in this work is unfeasible. but it is likely that the reduction of metal ions bound on PVP form a thin metallic hollow nanostructures and subsequent growth of this shape occurs from both sides of the shell by further reduction of metal ions in the bulk water and those in the inside of the hollow nanocrystals as observed in Figure 6 . The fast nucleation and growth processes seem to be important factors for the formation of hollow nanoparticles. since an instantaneous reduction of metal ions took place in the presence of large excess of the reducing agent in comparison to the metal precursors.

The syntheses of hollow metallic nanoparticles are limited to a few approaches. The most common methods involve the deposition of metal onto solid nano-template metal, silica and other materials and subsequent removal of the templating core by dissolution or calcination, and the galvanic replacement reactions. The coassembly of metallic nanoparticles with organic molecules have been employed to construct hollow nanospheres. ${ }^{29}$ An interesting method for making hollow $\mathrm{Pt}$ nanoparticles using templating riposomes containing photocataly st molecules has been recently reported. ${ }^{3 i \cdot}$ Hollow Gold nanocubes have also been prepared by electron beam reduction. ${ }^{31}$ Our method is a unique, novel. and important addition to the syntheses of hollow metallic nanoparticles.

\section{Conclusion}

The first șythetic examples of hollow $\mathrm{Sn}$ and $\mathrm{Pb}$ nano- 
structures have been shown in aqueous solution and at room temperature by one-step synthetic methods. The order and speed of mixing of the reactants between the metal precursorPVP and the reductant solutions and stoichiometry of all the reactants are crucial factors for the formation of the hollow nanocrystals. The hollow lead nanoparticles are so reactive that it could be used for making other hollow. inorganic. and derivatized. lead nanomaterials. We anticipate our approach will provide new opportunities in the preparation of varieties of hollow nanoparticles by simple. one-pot sy'nthetic reactions. We are currently investigating the generality of our method for the preparation of metallic hollow nanoparticles.

Supporting Information Available. Synthetic procedures. $\mathrm{XRD}$ data of composite hollow $\mathrm{Pb}$ nanocrystals and the sample holder. TEM images and SAED patterns of $\mathrm{Sn}$ and $\mathrm{Pb}$ nanoparticles. ${ }^{1} \mathrm{H}$ NMR spectra of mpy. SnCl $\mathrm{Sn}_{\beth}-\mathrm{mpy}$. $\mathrm{Pb}(\mathrm{OAc})_{-} \cdot 3 \mathrm{H}_{2} \mathrm{O}-\mathrm{mpy}$. and $\mathrm{Pb}(\mathrm{OAc})_{2} \cdot 3 \mathrm{H}_{2} \mathrm{O}$. and IR spectra of $\mathrm{PVP}, \mathrm{Pb}(\mathrm{OAc})_{2} \cdot 3 \mathrm{H}_{2} \mathrm{O}$, SnCl $\mathrm{Sn}_{2}-\mathrm{PVP}, \mathrm{Pb}(\mathrm{OAc})_{2} \cdot 3 \mathrm{H}_{2} \mathrm{O}-\mathrm{PVP}, \mathrm{Sn}$ nanoparticle-PVP, and $\mathrm{Pb}$ nanoparticle-PVP.

Acknowledgments. This work was supported by the Korea Research Foundation Grant funded by the Korean Govemment (MOEHRD: KRF-2005-20l-C0002 I) and by the Nano R\&D program (Grant 2005-02618) of the Korea Science and Engineering Foundation (KOSEF) funded by the Korean Ministry of Science \& Technology (MOST). This work was also supported in part by the SRC program (Grant R1 1-2005008-00000-0) of the KOSEF through the Center for Intelligent Nano-Bio Materials at Ewha Woman`s University. We thank the staff of KBSI and KAIST for assistance with TEM analyses and Dr. S.-T. Hong of LG Chem. Ltd. for XRD analyses. Prof. D. G. Churchill of KAIST is acknowledged for his proofreading of this manuscript.

\section{References.}

1. Kinn, S.-W.; Kim, M.; Lee, W. Y.: Hyeon, T. J. Am. Chem Soc. $2002,124,7642$.

2. Liang, H.-P; Zhang, H.-M; Hu, J.-S; Guo, Y.-G.; Wan, L.-J.; Bai, C.-L. Angew. Chem. Int Ed. 2004, 13, 1540.

3. Yang, J.: Lee, J. Y.; Too, H.-P.: Valiyavettil, S. J. Phys. Chem. $B$ 2006, 110,125
4. Mathiowitz, E.: Jacob, I. S.: Ion, Y. S.: Carino, G. P.; Chickering, D. E.; Chaturvedi, P.; Santos, C. A.; Vijayaraghavan, K.; Montgomery, S.; Bassett, M.; Morrell, C. Nature 1997, 386, 410.

5. Son, S. J.: Reichel, J.; He, B.: Schuchman, M.: Lee, S. B. J. Am. Chem. Soc. 2005, 127, 7316.

6. Im, S. H.; Teong, U.; Xia, Y. Nature Mater 2005, f, 67I

7. Rapoport L.; Bilik, Yu.; Feldman, Y.; Homyonfer, M.; Cohen, S. R.: Tenne, R. Nature 1997, 387,791.

8. Yin, Y.; Rioul, R. N.; Erdonmez, C. K.; Hughes, S.: Somorjai, G. A.; Alivisatos, A. P. Science 2004, 304, 711 .

9. Sun, Y.; Mavers, B.; Xia, Y. Adw Mater: 2003, 15, 641.

10. Yin, Y : Erdonmez, C.: Aloni, S.; Alivisatos, A. P.J. Am. Chem. Soc. 2006, 128, 2671 .

11. Sun, Y.; Mayers, B.: Xia, Y. Xano Lett. 2002, 2, 481

12. Kim, S. J.: Ah, C. S.: Jang, D.-T. Adv . Hater: 2007, 19, 1064

13. Mayers, B.: Tiang, X.: Sunderland, D.: Cattle, B.; Xia, Y. J.Am. Chent Soc. 2003, 125, 13364

14. Liang, H.-P.; Guo, Y.-G.; Zhang, H.-M.; Hu, J.-S.; Wan, L.-T.; Bai, C.-L. Chem. Comm 2004, 13, 1496.

15. Breen, M. L.: Dinsmore, A. D.; Pink, R. H.; Qadri, S. B.: Ratna, B. R. Langmin 2001, 17, 903.

16. Liang Z. J.; Susha, A.; Caruso, F. Chent Mtoter 2003, 15, 3176.

17. Tiang, P.; Bertone, J. F.; Colvin, V. L. Science 2001, $291,453$.

18. Prodan, E.; Radloff, C.; Halas, N. J.; Nordlander, P. Science $2003,302,419$.

19. Lu, L. H.: Capek, R.; Komowski, A.; Gaponik, N.: Eychmuller, A. Angew. Chent. Int. Ed. 2005, 4t, 5997.

20. Casella, M. L.; Siri, G. T.; Santori, G. F ; Ferretti, O. A. Longmuir 2000, 16, 5639

21. Noh, M: Kim, Y: Kim, M. G.: Lee, H.: Kim, H.; Kwon, Y.; Lee, Y.; Cho, J. Chem Mater. 2005, 17,3320 .

22. Hsu, Y. I.; Lu, S.-Y.: Lin, Y.-F. Small 2006, 2,26

23. Yang, C.-S.; Liu, Y. Q.; Kauzlarich, S. M. Chem. Moter $\mathbf{2 0 0 0}$ 12,983 .

24. Kittel, C. Introduction to Solid State Phusics; John Wiley \& Sons: New York, 1996.

25. Wang, Y.: Xia, Y. Nano Lett. 2004, 4, 2047.

26. Veith, M.; Frères, J; König, P.; Schütt, O; Huch, V; Blì, J. Eur: J. horg. Chemt $2005,3699$.

27. Vasquez, Y.; Sra, A. K.; Schaak, R. E. J. Am. Chem. Soc. 2005, 127, 12504

28. Borodko, Y.: Habas, S. E:; Kobel, M: Yang. P.: Frei, H.; Somoriai, G. A. J. Phys. Chent B 2006, 110, 23052.

29. Wong, M. S.; Cha, J. N.; Choi, K.-S.; Deming, T. T.; Stucky, G. D. Nano Lett. 2002, 2, 583.

30. Song, Y.: Garcia, R. M.; Dorin, R. M.: Wang, H.: Qill, Y.; Shelnutt, J. A. Angew. Chem. Int. Ed. 2006, 45, 8126.

31. Halder, A.; Ravishankar, N. J. Phys Chem B 2006, 110,6595. 